\title{
LA MIRADA SOBRE LOS BORJA (NOTAS CRÍTICAS PARA UN ESTADO DE LA CUESTIÓN)
}

\author{
Santiago LA PARRA LÓPEZ
}

Del escándalo al tópico, pasando por la caverna

La producción literaria sobre los Borja es amplísima, casi inabarcable, y continúa enriqueciéndose cada año con nuevos títulos ${ }^{\natural}$. El último entre nosotros es la reciente recreación teatral Borja, Borgia, en la que Manuel Vicent nos presenta a Maquiavelo como psicoanalista de Rodrigo de Borja (Papa Alejandro VI) en Nueva York con el transfondo del desfile de la victoria tras la Guerra del $\mathrm{Golfo}^{2}$. La razón de esta permanente atracción puede ser el que, aún sin haber merecido la atención de Shakespeare, pocas figuras histórico-literarias han acabado por encarnar como ellos la ambición, la codicia, la sensualidad o cualesquiera de las más bajas pasiones humanas, lo que siempre será actualidad mientras el género humano pueble el planeta. A mayor abundamiento (o acaso sea por eso mismo) los Borja mantienen intacto su gran atractivo comercial y buena prueba de ello es el título engañoso con el que se presenta la obra de Jacques Heers: aunque la versión original francesa ( $A$ la cour pontificale au temps des Borgia et des Medicis. 1420-1520) se intitula de manera algo más matizada que la traducción castellana (La corte de los Borgia), se trata en realidad de una obra de divulgación sobre Roma y el Papado tras la vuelta de Avignon (1420, con Martín V) que poco tiene que ver con los Borja. A Calixto III, primer Papa de esta familia, apenas si se le cita en un par de ocasiones y, desde luego, también se habla más de Martín V o de Pío II (que, por cierto, tampoco eran Medicis) que del propio Alejandro VI.

Indefectiblemente, pues no puede ser de otra forma, los Borja no son para nosotros sino como los vemos y con demasiada frecuencia en su retrato se abusa del 
trazo grueso sin matices, de modo que acaban convertidos en personajes radicales, extremados ${ }^{3}$, siempre próximos a la simplificación caricaturesca en cuanto que prototipicos: Alejandro VI encarnaría, así, la depravación sacrílega y el desenfreno; César, genuino modelo del principe maquiavélico, la ambición sin escrúpulos y la crueldad, mientras Lucrecia, el elemento femenino de esta tríada maligna, queda reducida a paradigma de la sensualidad sin límites... Aunque la mirada cambia con los tiempos (la famosa Lucrecia de Victor Hugo -a la que Donizetti puso música para su ópera- no le parecía a Gregorovius sino una "repulsiva creación"), la imagen más extendida hoy todavía de los Borja es la que asocia con el escándalo a este apellido. al menos en su versión italianizante -Borgia-, ya que no (sino más bien todo lo contrario) en el Borja autóctono.

No aspiramos, desde luego, a que esta observación avale nuestra perspicacia por su originalidad, pues el identificar a los Borgia con conductas escandalosas ha devenido en un lugar común del que sistemáticamente se pretende huir al abordar el tema. Este "sambenito", convertido en tópico hoy (aunque no carezca de motivación fundada), nació en el tiempo mismo de sus protagonistas. Así, autores coetáneos como el veneciano Girolamo Priuli, los cronistas napolitanos J.Sannazaro y Pontano, el famoso historiador F.Guicciardini (embajador que fue en España) o Paolo Giovio (familiar del propio Alejandro VI y luego obispo de Nocera) nos legaron una visión negra de los Borgia en general y de Lucrecia en particular (a la que tachaban abiertamente de meretriz), si bien más fundada en la tradición popular que en la observación propia de los hechos que narran pues casi ninguno de ellos vivió en Roma.

Caso aparte es el del alsaciano J. Burkhardt (o Bucardo), maestro de ceremonias de Alejandro VI, cuyo Liber Notarum sigue siendo fuente imprescindible y recurrente para el pontificado del segundo Papa Borja. Persona minuciosa en su quehacer, pero rencoroso, antipático y muy susceptible, su obra ha merecido juicios contrapuestos. Así, Gregorovius, por ejemplo, se niega a considerarlo autor antiborgiano aduciendo que, en realidad, él sólo recoge en su Diario dos hechos verdaderamente escandalosos (la famosa orgía vaticana conocida como el "baile de las castañas" -que M. Vicent transforma en el "de las bellotas"- y la carta a Saveili), pero los toma de otras fuentes. Y, por cierto, aunque hoy día está admitida la falsedad de ambos, ello no obsta para que se repitan como verdaderos en la mayor parte de las obras a la venta. Pero otros no opinan como el autor alemán: S.SchûllerPiroli entiende que ésta sería "la fuente principal de esa leyenda demoniaca que le acusaba [a Alejandro VI] de practicar la magia negra y de todos los crímenes imaginables del antipapa entregado al diablo" (p.: 192); a $\mathrm{M}^{\mathrm{a}}$ Bellonci el autor le parece "pedant $i$ ordenat" y su obra "sembla que tinga la voluntat expressa d'embolicar els judicis", aunque también reconoce que "procurava sobre tot ser precís... i que si hagués volgut farcir el seu llibre de testimoniatges contra els Borja, li hauria resultat facilissim només deixant anar una mica la mà" (pp.: 68 y 287); para M. Menotti, en fin, el maestro de ceremonias del Papa (a quien erróneamente le cambia este cargo por el de mayordomo) era "home de talent comi i de cultura 
mediocre, que potser tenia el desig de ser diligent i conscienciós; però, jail'. l'amor pel vi dels pujols del Laci molt sovint n'emboira la ment i compromet la seriositat de les seues afirmacions" (p.: 51).

Hubo también, por contra, otros autores coetáneos mucho más benévolos para con los Borgia (a alguno de los cuales parece que Lucrecia pudo conocer hasta en sentido bíblico cuando vivía en Ferrara), el más famoso de los cuales sería L. Ariosto, pero también los Strozzi (Tito y Ercole), Pietro Bembo, Aldo Manuzio o Tebaldeo.

Tras un relativo olvido durante los siglos siguientes (Cfr.: el magnifico estudio de M.Hermann), los Borja resurgen con fuerza en la literatura romántica, que los encuentra literalmente apasionantes. Con el Positivismo, en cambio, se impondrá un calculado distanciamiento respecto al tema para trasladarlo del ámbito de la pasión subjetiva al campo de la razón fría y pretendidamente objetiva. Su meta es la verdad, de manera que, por ejemplo, el más destacado de estos autores "borgianos", F. Gregorovius, advertía que su propósito era estudiar la figura de Lucrecia "de acuerdo con los métodos históricos más rigurosos, es decir, a la luz de documentos indiscutiblemente auténticos" y no ocultaba su satisfacción por los resultados obtenidos: "creo haber conseguido -afirmaba rotundamente- sustituir una novela por un relato histórico"s.

La prevención calaría hondo y, a partir de aquí, la primera preocupación de los muchos y tan diferentes autores que se han venido ocupando de estos personajes ya no será tanto el parecer pro o anti-borgianos sino el mantener ese distanciamiento (al menos formalmente) que les aleje de los aspectos morbosos e insertar el tema en su época como antídoto frente al escándalo que antaño causaban algunas de aquellas conductas ${ }^{6}$.

Lamentablemente, empero, esto suele devenir luego más en un mero buen deseo que en una realidad. Así, por ejemplo, casi cien años después que Gregorovius, también Ivan Cloulas aspira en nuestros días a que "los destinos individulales" de sus protagonistas se inserten en el contexto histórico en el que se desenvolvían, para "señalar la evolución de los comportamientos y las mentalidades, frente a los golpes de la suerte, y hacer resaltar las interferencias entre las pasiones privadas y los vastos cambios producidos en la sociedad" (p.: 398). Mucho nos tememos, sin embargo, que quede muy lejos de haber logrado objetivos tan loables. Antes bien, una vez más nos hallamos ante un relato lineal (por no decir ramplonamente positivista), que añade poco a lo ya dicho antes por otros autores, pues no en balde se recurre a las mismas fuentes -no siempre las originales, además- aunque la ausencia de notas a pie de página nos priva de conocer cuáles son las que utiliza el autor en cada momento. En consecuencia, el resultado viene a ser una mera yuxtaposición de anécdotas, de unos episodios que el lector mínimamente avezado en el tema puede incluso ir adivinando de antemano a medida que avanza en la 
lectura. Y ni siquiera todas las informaciones que llenan las páginas de este libro han sido sometidas al tamiz de la crítica, como lo prueba el que se dé por buena la presunta ascendencia real de los Borja como descendientes de D. Pedro de Atarés (p.:16) o acepte reiteradamente (en págs.: 18 y 36) la supuesta profecía hecha por San Vicente Ferrer a Alfonso de Borja (e inventada por éste) de que llegaría a Papa, haciéndolo a él santo, y asevere que fue Calixto III en 1458 (y no Inocencio VIII en 1492) quien elevara la sede valenciana a la categoría de metropolitana (p.: 51). Algunas de sus interpretaciones adolecen de tan poco fundamento como, por ejemplo, el insistir en que la doble corona de los Borja (símbolo alejandrino adoptado profusamente por los duques de Gandia) fuese en realidad una corona que lanza dardos de acero al suelo (págs.: 118 y 121) y, en fin, si el autor se hubiera molestado en conocer un poco más a fondo las investigaciones (ineludibles sobre el tema) del P. Batllori, sin duda no escribiría "Mazalanes" por "Massalavés", "Arenas" por "Arenós" (p.: 24), al duque de Segorbe no lo haría "duque de Segovia" (p.: 375) y, desde luego, tampoco citaría así este artículo de Batllori: "La correspondencia d'Alexandre VI ambels seis familiars y ambels Reis Catòlicos" (sic, p.: 396).

Pese a todo, esta obra ha debido interesar tanto a J. Robichon que la ha tomado como base (y sospechamos que aún algo más que esto) para su novela histórica (?) sobre la trilogía Alejandro-César-Lucrecia, en donde a las confusiones de Cloulas se añaden algunas otras propias, como situar a Xàtiva en el reino de Aragón (p.: 18), afirmar que el arzobispo de Valencia era el primado de España (p.: 45) o dar por sentado que tras el asesinato de su marido (el II duque de Gandia) María Enríquez vivió encerrada "en una soledad austera y vengativa..., entregando su vida a Dios y a sus hijos" (p.: 367), lo que da una imagen de esta activa viuda aproximadamente en las antípodas de la realidad, habida cuenta su frenética actividad como duquesa regente de Gandia hasta la mayoria de edad de su hijo, como muy bien ha demostrado José Luis Pastor Zapata.

Tampoco añaden mucho más al conocimiento de los Borja otras publicaciones como la también traducida de Collison-Morley, cuya difusión resultaria incomprensible si no fuera por el aludido gancho comercial del tema, y sobre la que no creemos necesario repetir aquí lo que ya hemos escrito en otro sitio al respecto ${ }^{7}$; o las recreaciones autobiográficas de Lucrecia, escritas en primera persona, a cargo de A. Cerezales Laforet y Carmen Barberá respectivamente (por más que la de esta última vaya ya por su cuarta edición al año de su aparición); o también la "chauvinista" e insulsa aportación de F. Almela y Vives, de la que su fecha de publicación no justifica el empeño del autor en, por ejemplo, presentar a Lucrecia como sobrina del Papa Alejandro VI, pretender que los primeros duques de Gandia habían nacido ya en Valencia, etc...

En esta misma línea, en fin, aunque el protagonista de la pretendida novela histórica de Hella S. Haasse es Giovanni Borgia (más conocido como el "Infans Romanus"), lamentamos constatar que las dos páginas que le dedica Maria Bellonci 
a este probable hijo incestuoso de Alejandro VI y Lucrecia nos resultan más clarificadoras que las casi 400 de la escritora holandesa...

De manera que, visto lo visto, al final resulta que la patriótica defensa que hace Blasco Ibáñez de esta familia valenciana en $A$ los pies de Venus, sin ser una novela magistral precisamente ${ }^{8}$, sí resiste la comparación con muchas de las publicaciones aparecidas en estos últimos 50 años $\mathrm{y}$, desde luego, es aún más claro que la síntesis de S. Schüller Piroli sobre los dos papas Borgia (aunque muy duramente juzgada por algún critico valenciano, y no sin razón en lo que le critica) está muy por encima de todos esos otros trabajos citados, pese a que su lectura se hace desagradable ( $\mathrm{y}$ a veces hasta ininteligible) debido a una pésima traducción (cosa también muy frecuente aqui) en la que los signos de puntuación se han distribuido de manera aleatoria, la sintaxis resulta sistemáticamente violada y ni siquiera faltan a esta cita de imperdonables despropósitos las faltas de ortografía.

El esquema argumental es siempre el mismo, una y otra vez, en esta literatura borgiana que sólo pretende ser objetiva: el autor de turno comienza por la descripción (exótica) de las tierras de la Costera, cuna de los primeros Borja; continúa con las "aventuras" italianas de éstos a partir de la elección de Calixto III (y aquí se repiten episodios archiconocidos, no siempre importa si verdaderos o falsos, sobre el nepotismo y las amantes de Alejandro, invasión de Italia por Carlos VIII, la cruel ambición de César, las desventuras matrimoniales de Lucrecia, el asesinato del duque de Gandia, etc...) para acabar con un breve epilogo referido a los Borja gandienses, duques de Gandia, o, mejor dicho, al duque San Francisco de Borja, proponiéndolo como contrapunto santo ante la depravación de sus antepasados ${ }^{9}$. Siempre es igual. En consecuencia, el resultado es también siempre el mismo, de modo que -como escribe M. Hermann-Röttgen- "el lector se pregunta, irritado, por qué motivo se vuelve a contar 'la misma' historia otra vez, ya que la mayoria de los autores no tienen nada nuevo que añadir. Pero parece que no deja de haber lectores y compradores interesados, ya que, cada veinte años, aparece más o menos el mismo libro que relata todos los hechos y todos los rumores, comentados con más o menos corrección ${ }^{10}$.

Hay también "otra historiografia" borgiana, ultramontana y obnubilada por un fanatismo reivindicativo empeñado en negar las más clamorosas evidencias, a la que no valdría la pena referirse, según esto, si no fuera por una reciente publicación que la ha resucitado hace poco entre nosotros, incomprensiblemente auspiciada por el Consell Valencià de Cultura. $\mathrm{Y}$ debemos apresurarnos a aclarar que queda al margen de este juicio nuestro la rigurosa pero incauta colaboración en esta obra colectiva de Mariano Peset (sobre "Alejandro VI y las universidades hispanas"), que felizmente desentona con respecto a lo que escriben ahí también A. Sánchez de la Torre (sobre "Alejandro VI, un Papa renacentista") y V. Castell (sobre "Las bulas alejandrinas: precedentes, génesis y efectos inmediatos", donde llama la atención el que ni tan siquiera se cite la investigación al respecto del P. Batllori y no nos sirve 
de excusa la apretada síntesis que exigia esta publicación). Resulta descorazonador, por ejemplo, el que a estas alturas todavía se pretenda cuestionar la paternidad de Alejandro VI como hace ahí A. Sánchez apoyándose en un autor tan desacreditado como O. Ferrara, diplomático cubano metido a historiador y sobre cuya obra el P. Batllori, en un juicio muy benévolo, afirma que "si compiace di rendere oscure le questioni chiare e di oscurare di più quelle di per sé oscure", por lo que el crítico muestra su convencimiento de que "nessuno storico andrà a consultare tale opera per la serietà delle sue richerche" (Obra Completa, 255-256).

Un puntal fundamental de esta historiografia rancia lo constituye la obra de Monseñor Pedro de Roo, que ejercería una gran influencia sobre las atrabiliarias "reivindicaciones" de Elías Olmos y Canalda, queriéndonos convencer ambos de que los hijos de Alejandro VI eran, en realidad, sobrinos nietos suyos. En esta misma línea, el editor de la obra de Gregorovius que manejamos aquí, A. Escarpizo, además de suprimir alegremente el corpus documental de la edición original, jalona esta versión con inefables apostillas suyas distribuidas en notas a pie de página, como ésta, por ejemplo (p.: 334), en la que culpa a "los escritores protestantes $y$ racionalistas" (sic) de la para él injustificada mala fama de Alejandro VI...

No debe extrañar, en fin, el que los más eximios y abundantes ejemplos de esta literatura borgiana montaraz los hallemos entre los hagiógrafos del IV duque de Gandia, San Francisco de Borja. Un noble, además de esta familia precisamente, que se hace religioso y acaba siendo canonizado es la excusa perfecta para los excesos nacionalcatólicos de un Adro Xavier (pseudónimo de Alejandro Rey Stolle, las sucesivas ediciones de cuya obra son un insulto al rigor y espiritu crítico). Sería injusto poner a su nivel el panegírico de Juan Pastor Gómez (escrito "...ad maiorem Dei gloriam"), pero ésta otra, desde luego, ni mucho menos supera la del también jesuita Pedro Suau (escrita a principios de siglo) ni, por supuesto, la más reciente de C. Dalmases (S.I). A la vista, por lo demás, de la del famoso exministro de Educación Cruz Martinez Esteruelas, la última de la que nosotros tenemos noticia, no acertamos a encontrar otro mérito científico en el autor para haber aceptado este encargo de la editorial que el hecho de que debe veranear en Jávea (lugar próximo a Gandia, cuna del santo, donde él mismo fecha el término de la obra), circunstancia que aprovecha para describir esta parte de la costa y sus grutas al narrar un idílico viaje en barca del IV duque de Gandia por esos parajes; pero ni siquiera esto tiene interés.

Huelga aclarar que el presente recorrido historiográfico por lo que podríamos denominar algo así como "del escándalo al tópico, pasando por la caverna", además de muy apretado es, desde luego, subjetivo $\mathrm{y}$, sin duda, incompleto (no sólo por razones de espacio, sino también porque algunos estudios ya clásicos sobre la materia, como los de W. Roscoe o Carlos Yriarte en concreto, no nos duelen prendas el confesar que aún no hemos tenido ocasión de consultarlos). Mucho nos tememos también que resulte tedioso, pero no quisiéramos parecer 
pesimistas ni ser injustos. Así, pues, confiamos en que haya quedado clara nuestra admiración por las aportaciones de Gregorovius y, siguiendo un hilo cronológico, juzgamos magnífica la obra de Maria Bellonci, centrada precisamente también en Lucrecia, que apareció en Italia en 1939 y en 1979 ya iba por la $16^{a}$ edición. Sus más de 600 páginas son presentadas como novela histórica, aunque por el rigor con que está documentada debe entenderse que la tal etiqueta de novela no obedecerá tanto a que la ficción se imponga a la realidad en el relato sino, en todo caso, por el estilo desenfadado con que está escrito, no exento de una dosificada ironía a veces $\mathrm{y}$, siempre, con una gran sensibilidad y perspicacia.

Por otra parte, como queda dicho, la investigación del P. Batllori sobre los Borja es ineludible ${ }^{11}$, particularmente en lo que se refiere a las intrincadísimas cuestiones de onomástica y genealogía de una familia como ésta, en la que (siguiendo los usos de la nobleza) la reiteración de los mismos antropónimos y los matrimonios entre parientes contribuyen a que no siempre se tenga del todo claro de qué cardenal se habla en cada momento o cuál es el parentesco exacto de dos personajes dados. Y aunque ahora, tras la aparición reciente del tomo IV de su Obra Completa, resulte más fácil y cómoda de consultar (por más que muchos de sus trabajos han aparecido repetidos, y algunos más de una vez, en publicaciones diferentes) queremos seguir pensando que aún tendremos ocasión de conocer el magno epistolario borgiano en el que lleva décadas trabajando este lucidísimo historiador, quien nunca oculta lo que esta empresa suya deberá a la paciente labor previa de Lluís Cerveró.

\section{El olvido de los Borja valencianos}

Uno de los lunares que más nos llama la atención y más nos preocupa en la literatura borgiana al uso es el olvido sistemático de la rama valenciana de esta familia, aunque en muchas ocasiones mejor sería que esa ausencia fuera total pues las alusiones marginales que se suelen hacer para salir del paso nos describen una Valencia exótica y unos personajes angelicales a modo de contrapunto -como deciamos- respecto a los depravados Borgia "italianos". Así, la misma SchüllerPiroli, por ejemplo, se muestra convencida de que San Mateo es "una localidad de la costa" (p.: 19) e improvisa una fabulosa historia, según la cual en 1484 "el rey Fernando habia mandado decapitar al último duque de Gandía de su linaje. Don Jaime de Aragón, porque éste se había atrevido a presentarse contra él como pretendiente de la corona" (pp.: 123 y 267); según J. Robichon: "al pie de la roca de Játiva se extendia un jardín de opulencia, los vergeles y cultivos de la huerta de Valencia, regidos por el 'Tribunal de las Aguas'..." (p.:19); no es ni mucho menos una excepción la incongruente suposición de Saint-Paulien de que "el paisaje (de Gandia) no debe de haber cambiado mucho desde los tiempos en que el 'el santo duque' lo recorria a caballo..." (p.: 316) (aunque a este autor no lo debemos tomar tampoco muy en serio, pues unas líneas más abajo añade: "aquí, hasta el más modesto cultivador es millonario")...; y todo esto, en fin, por no referirnos a las 
variopintas denominaciones que la mayoria de estos autores atribuyen al idioma hablado en el Vaticano de los Borja, sin que inconsecuentemente alcancen a relacionarlo con la denominación genérica de catalani que allí se les daba...

No negaremos que la reiteración de este tipo de alusiones acaba por resultarnos un punto indignante y habrá que ser muy miope para confundir semejante atentado al sentido común y al rigor histórico con una herida en nuestro "chauvinismo". De todas formas, lo que más nos interesa aquí no es tanto lamentarnos como el hacer una llamada al interés de la investigación sobre los Borja desde esta otra orilla, la valenciana, la más próxima a nosotros, la menos explotada hasta ahora y la que, en estos momentos, más luz nos puede arrojar sobre el tema (porque, además, ya estamos cansados de oír las mismas cosas sobre los mismos personajes). Es precisamente esto lo que nosotros mismos hemos intentado en nuestra modesta y aún incipiente investigación centrada en torno a los duques de Gandia.

No se trata, desde luego, de que la tarea sea responsabilidad exclusiva de nosotros, los valencianos, pero es también nuestra (quizá en primer lugar) incluyendo a nuestras instituciones, como es obvio. En este sentido, no cabe duda de que sí se han llevado a cabo algunas realizaciones en estos últimos años, pero nos parecen insuficientes (y hasta poco afortunada alguna de ellas más reciente). Así, por ejemplo, cuando en 1985 se cumplían los 500 años de la adquisición del ducado de Gandia por Alejandro VI, la única iniciativa para recordar el acontecimiento fue la publicación del libro de Martí Domínguez ${ }^{12}$ por el CEIC "Alfons El Vell" de Gandia.

Fueron más, como es lógico, las actividades que conmemoraron en 1992 "el otro V Centenario" (la coronación papal de Rodrigo de Borja), pero ni muchísimo menos podemos tampoco sentirnos satisfechos del todo: la IVEI sacó a la luz entonces la obra de Schüller-Piroli y una apretada síntesis (Els Borja. Espill del temps) a cargo de Ximo Company que cumple perfectamente su función divulgativa y se une a las otras investigaciones, verdaderamente magníficas, de este autor sobre el mecenazgo artístico de los duques de Gandia y su aportación en la tardía transición del gótico al Renacimiento en nuestras tierras. Para esta misma ocasión el CEIC Alfons El Vell de Gandia encargó a M. Boix unas espléndidas esculturas de los papas Borja, de César, Lucrecia y del IV duque de Gandia vestido con hábito de jesuita, que esperamos ver pronto en el lugar más idóneo de nuestra ciudad reproducidas a tamaño natural.

Por una vez también la iniciativa privada se sumó a la celebración y, así, la Fundació Cultural de Bancaixa editó, en versión castellana y valenciana, la vieja obra de Mario Menotti ${ }^{13}$, si bien enriquecida con oportunas y necesarias puntualizaciones por parte de M. Batllori y X. Company, así como con un sugerente estudio iconográfico de los apartamentos vaticanos de los Borja a cargo de M.Carbonell. La Nadala de la "Fundació Jaume I" de Barcelona trataba monográficamente para esta 
ocasion sobre Els Borja, un llinatge universal dels Països Catalans e igualmente la revista Afers les dedicó un tardío monográfico en su número 17 de 1994.

En el congreso organizado por la Universidad de Sttutgart en Schwäbische Hall (mayo de 1992) se "agarbellava -dice Batllori- història y llegenda, biografia y pamflet, art y caricatura, amb un cert predomini numèric deis segons dels dos components d'aquests epitets aparellats. Però amb una actitut, tant per part dels organitzadors com dels assitents, més aviat crítica y seriosa que no pas pamfletística $y$ adversa"14. De lo que no hay duda es del alto interés que tuvo el simposio internacional que la "Fundació Ausiàs March" organizó en Valencia en octubre de 1994 con motivo de la entrega de los premios anuales que llevan el nombre de ese mes en su edición número 23. Al margen de nuestra ponencia presentada ahí, las actas de esta reunión (que, por cierto, pasado ya un año aún no se han publicado) constituirán, sin duda, una de las aportaciones más interesantes en estos últimos años al tema de los Borja y su época.

Más recientemente, en fin, a principios de este año 1995, estuvo abierta en Xàtiva la exposición Xàtiva, els Borja: una projecció europea. Los dos volúmenes del catálogo que la acompañan son verdaderamente magníficos, pero ya hemos explicado en otro lugar (Cfr.: Revista de Gandia del 12/IV/1995) nuestra profunda decepción por el hecho de que, sin dejar de reconocer el evidente gran éxito de dicha exposición, una iniciativa de este tipo se hubiera planteado con sólo una consideración muy marginal (en nuestra opinión) para con la otra rama valenciana de este familia: los duques de Gandia. Nos parece incongruente, se mire por donde se mire (empezando por el propio plano científico y acabando, si se quiere, hasta por el de una política cultural coherente). Lamentamos, sobre todo, el que quedara desaprovechada así una ocasión tan estupenda (y aún no alcanzamos a comprender el por qué) de profundizar en la tan urgente reivindicación de los Borja valencianos. Porque, entre otras cosas pero fundamentalmente, los Borgia resultan incomprensibles sin los Borja, y viceversa. Esto, que es claro para nosotros, seguramente también lo sería para J. Sanchis Sivera cuando se decidió a publicar el epistolario del Papa Alejandro VI con su hijo Juan, II duque de Gandia, facilitándonos un documento precioso y fundamental para entender la compleja personalidad de Rodrigo Borja.

La última de las evidencias que vienen a corroborar lo que estamos diciendo nos la proporciona la ejemplar investigación de un joven historiador: Luis P. Martínez ha podido demostrar que la meteórica carrera de Alfonso de Borja, hasta acabar en el solio de San Pedro como Calixto III, no solamente no tuvo nada que ver con las supuestas profecías en este sentido de San Vicente Ferrer (como, por lo demás, debería enseñar el sentido común), sino más bien que a sus servicios como asesor jurídico del Magnánimo cuando el Cisma de Occidente habría que añadir otro tipo de servicios mucho más prosaicos (incluidos oportunos y graciosos subsidios monetarios) en aquel complejo contexto político donde cabe incluir también la guerra contra Castilla. 
Sólo así, en fin, serả como avanzaremos en el conocimiento de los Borja, y no repitiendo por enésima vez lo que ya sabemos por los cronistas coetáneos o, peor aún, lo que otros ya han escrito. 


\section{NOTAS}

I.- M. Hermann-Röttgen, por ejemplo, se admira de que sólo en Alemania hayan aparecido seis libros sobre el tema entre 1988 y 1991.

2.- La idea resuita tan original como sugerente, pero no nos parece (contra la opinión de E. Haro Tecglen en cl suplemento "Babelia" de El País del 17/VL/1995) que no se resuelva tan brillantemente como suele ser habitual en otros textos de este perspicaz autor. Por otra parte, nos resulta incomprensible el que ía obra se estrenara mutilada (se suprimen los personajes del "Empleado". "Chico neoyorquino" y la "Chica neoyorquina") en la versión de Moma Teatre en el teatro Rialto de Valencia (24 febrero-12 de marzo de 1995).

3.- "Lucrecia Borgia es la más desventurada figura de mujer de toda la historia moderna", así comienza, por ejemplo, Gregorovius su estudio sobre ella.

4.- Muchos coetáneos, como el dietarista M. Sanudo, estaban convencidos de que Rodrigo de Borja había firmado un pacto expreso con el diablo Babuino para ser elegido Papa y asi se lo transmitía, por ejemplo, el marqués de Mantua a su esposa en carta del 22 de septiembre de 1503, en la que le narraba la agonia del Pontífice (Cfr. Gregorovius, p. 345).

5.- Lucrecia..., 23. Hermann-Röttgen, sin embargo, no lo juzga así, pues según ella "no logró una auténtica obra histórica... sino que creó una ficción, un retrato literario en el mejor de los casos" (La familia..., 127-128).

6.- Algunos, desde luego, permanecerán al margen de estas preocupaciones. Es el caso, por ejemplo, de Apollinaire, cuya novela sobre La Roma de los Borgia suponemos que se recuerda más por el apellido de su autor (y se olvida que la escribió con René Dalize) que por lo ajustado de su trasfondo histórico y aủn su misma calidad literaria, pues ambos aspectos dejan mucho que desear. Es como si no hubieran pasado los 50 años que transcurren desde la aparición de la Lucrecia... de un tal Fernandez y González, folletín cuyo título escandaloso lo sugiere todo.

7.- Cfr. nuestra reseña en Ullal, 4 (Gandia, Tardor de 1983), p. 112.

8.- Debe tenerse en cuenta, ađemás, que en la fecha en la que escribe Blasco (año 1926) todavía no habían aparecido algunos de ios estudios fundamentales sobre los Borja. Es claro que si conocía las obras de V. Hugo, Gregorovius o Roscoe, no así la de M. Menotti (pues afirma, por ejemplo, que no se conoce retrato alguno de Vannozza Cattanei) y es posible que leyera, además del relato del viaje de Münzer por Valencía, algunas otras crónicas coetáneas como la de Guicciardini, Gaspare de Verona (quien fue preceptor de Rodrigo de Borja cuando éste estudiaba en Bolonia) o Infessura. Por otra parte, el personaje del canónigo D.Baltasar Figueras, tio del protagonista de su novela, es sin duda D. José Sanchis Sivera, a cuyo interesantísimo epistolario entre Alejandro VI y el II duque de Gandia, su hijo, se refiere en la novela aún sin citarlo expresamente.

9.- Ésta es la tesis (perfectamente sugerida ya en el título) que pretende defender Saint-Paulien en su, por lo demás intranscendente, hagiografía del IV duque de Gandia y lo mismo que piensan otros muchos autores. Así, por ejemplo, escribe I.Cloulas: "En tanto que, bajo el nombre de los Este de Ferrara, los hijos de Lucrecia hacen revivir en Italia la grandeza mundana de los Borgia, la rama española de su linaje ofrece, en un giro prodigioso, el modelo de las virtudes cristianas, a la vez que la historia ejemplar de una familia de la mejor nobleza, en el despertar de los tiempos modernos" (p. 350. Negrita es 
nuestra). En algún otro lugar hemos manifestado ya nuestro desacuerdo con este enfoque, por lo que no insistiremos más en ello (Cfr. "Francisco de Borja, duque antes que santo", o "Les Borja...").

10.- La familia.... 175. Mucho antes que ella, en 1926, Blasco Ibáñez ya observaba en su alegato proborgiano cómo "los historiadores imparciales encontraron más cómodo llegar hasta nuestros días copiándose unos a otros de un modo automático, sin examinar antes la autenticidad y veracidad de los relatos antiguos" ( $A$ los pies..., parte I, cap. II).

11.- Es por ello por lo que nos resulta especialmente llamativo el que Ricardo García-Cárcel omita esta parcela en la investigación del P. Batllori cuando hace un repaso, aún somero, de sus preocupaciones como historiador en el Prólogo (p. IX) a Humanismo y Renacimiento. Estudios hispano-europeos, Ariel, Barcelona, 1987.

12.- Se trata básicamente de una vieja sintesis de muchas lecturas, en la que la aportación propia más destacable puede ser la descripción del estado actual de determinados escenarios borgianos y la no disimulada antipatia del autor para con Fernando El Católico (acaso por su enfrentamiento político con Alejandro VI). A propósito de esta edición, aclararemos ahora (por vez primera) que los cuadros genealógicos que acompañan a la breve introducción que hicimos nosotros guardan un asombroso parecido con los que publicó la revista El Temps en unos coleccionables sobre los Borja (a cargo de F. Javier Puertas) y luego reproducidos por F. Mira, quien sí cita de dónde los toma él, en el apéndice a su traducción de la obra de $\mathrm{M}^{3}$. Bellonci.

13.- Cfr. la detenida reseña de Enric Soria en Afers, 17 (Catarroja, 1994), pp. 186-194.

14.- Presentación a la obra de $\mathrm{M}^{\mathrm{a}}$. Bellonci que citamos aquí, p. 12. 


\section{BIBLIOGRAFÍA CITADA}

- ADRO XAVIER (pseudónimo de Alejandro Rey Stolle), El duque de Gandía, Casals, Barcelona, 1986, $5^{\mathrm{a}} \mathrm{ed}$.

- ALMELA Y VIVES, Francisco, Lucrecia Borja y su familia, Juventud, Barcelona, 1943.

- APOLLINAIRE, Guillaume, La Roma de los Borgia, Icaria, Barcelona, 1981, 24 ed. (1977) (Ed. original en francés, 1913, escrita en colaboración con R.DALIZE).

- BARBerÁ, Carmen, Yo. Lucrecia Borgia, Planeta, Barcelona, 1990, 4a ed. (1989).

- BATLLORI, Miquel (S.I), La família Boria, vol. IV de su Obra Completa (ed. a cargo de E.Duran y J. Solervicens), Eliseo Climent Ed., València, 1994. No se recogen aquí algunas colaboraciones del autor en enciclopedias y otras menores de carácter divulgativo, asi como tampoco su The Papal Division of the World and its Consequence, en First Image of America. The Impact of the New World in the Old, ed. de F. Chiappelii, University of California Press, Berkley-Los Ángeles-Londres, 1976, pp.: 211-220, que se incluirá en el vol.XIV de esta colección (hay traducción al castellano por la Universidad de Caracas, 1979, y una pequeña sintesis en Saó, monográfico nº 5 sobre "Els Borja", 1990, pp.:14-17).

- BLASCO IBÃÑEZ, Vicente, A los pies de Venus, en Obras Completas, Aguilar, Madrid, 1972, III, 1.017-1.180 (escrita en 1926 como continuación de El Papa del mar, Ibid., pp.: 885-1.016, escrita en $1925)$.

- CEREZALES LAFORET, Agustín, Lucrecia Borja, máscara de sombras, Exadra de Ediciones, Madrid, 1989.

- ClOULAS, Ivan, Los Borgia, Javier Vergara Ed., Buenos Aires, 1988 (ed. original en francés: 1987).

- COLLISON-MORLEY, L., Los Borgia La turbulenta historia del Papa español Alejandro VI y de sus hijos César y Lucrecia), Acuario, Barcelona, 1982.

- COMPANY Y CLIMENT, Ximo, "Pau de Sant Leocadi y la seua obra gandiana", Guaila (después Ullal), 1 (Gandia, 1982), 35-47.

-Id., junto con A.J.PITARCH, "La Col.legiata de Gandia: Sociologia d'un espai", Ullail, 4 (Gandia, 1983), $52-65$.

-Id, Pintura del Renaixement al Ducat de Gandia. Imatges d'un temps y d'un pais, IVEI, València, 1985. -Id., Els Borja. Espill del temps, IVEI y CEIC "Alfons El Vell", València, 1992.

- DALMASES, Cándido (S.I), El Padre Francisco de Borja, BAC Popular, Madrid, 1983.

-Id., "Francesc de Borja y la cultura", Ullal, 4 (Gandia, 1983), 49-51.

- DOMingueZ, Marti, Els Borja, CEIC "Alfons El Vell", Gandia, 1985.

- FERNÁNDEZ Y GONZÁlEZ, Manuel, Lucrecia Borgia (Memorias de Satanás). Novela histórica original, por... El Mercantil Valenciano, Valencia, s/a (escrita en 1865), 2 tomos en un volumen.

- FERrara, Orestes, El Papa Borgia, La Nave, Madrid, 1943, $2^{\mathrm{a}}$ ed.

- GONZÁleZ BALDOVÍ, Mariano y PONS ALÓs, Vicent (eds.), Xàtiva, els Borja: una projecció europea, Ajuntament de Xàtiva, Col.legiata de Xàtiva, Generalitat Valenciana y Diputació de València, Xàtiva, 1995, 2 vols. 
- GREGOROVIUS, F., Lucrecia Borgia. Segín los documentos y correspondencias de su propio tiempo, Lorenzana, Barcelona, 1970, $2^{a}$ ed. (versión original en alemán: 1874. Traducción y ed. de A. Escarpizo).

- HAASE, Hella S., La ciudad escarlata, Edhasa, Barcelona, 1993 (ed. original de 1953).

- HEERS, Jacques, La corte de los Borgia, J. Vergara Ed., Buenos Aires, 1970 (ed. original en francés: 1986).

- HERMANN-RÖTTGEN, Marion, La familia Borgia. Historia de una leyenda, IVEI, València, 1994 (versión original en alemán: 1992).

- LA PARRA LÓPEZ, Santiago. "Entre el Renaixement y el Barroc: l'època dels Borja", en El Llibre de la Safor (ed. de Néstor Novell), Gandia, 1983, pp.:267-274.

- Id.. Los Borja y los moriscos. (Repobladores y 'terratenientes' en ia Huerta de Gandia tras la expulsionn de los moriscos), IVEI, Valencia, 1992.

- Id. (en colaboración con J.M. BORJA), La imagen de los Borja, Producciones Altair Gandia, 1993.

- Id., "Els Borja, ducs de Gandia", Afers. Fulls de recerca y pensament, 17 (Catarroja, 1994), pp.: 11-29.

- Id., "Les Borja, entre el palau y el convent", Espai Obert. Revista d'assaig i investigació, l (Gandia, 1994), 86-91.

- Id., "Francisco de Borja, duque antes que santo", Simposi sobre els Borja ("23 Premis Octubre"), València, 1994, en prensa.

- MARTÍNEZ, Luis Pablo, "La promoció d'Alfons de Borja al bisbat de València y la política d'Alfons el Magnànim. Esglèsia y finances estatals a l'entorn de la guerra de Castella de 1429-1430", en Xàtiva... (ed. de González Baldoví y Pons Alós), I, 277-290.

- MARTÍNEZ ESTERUELAS, Cruz, Francisco de Borja, el nieto del escándalo, Planeta, Barcelona, 1988.

- MENOTTI, Mario, Eis Borja (ed. a cargo de M. Batlori y X. Company, con un estudio de Marià Carbonell), Bancaixa, València, 1992 (también en versión castellana) (ed. original en italiano: 1917).

- OLMOS Y CANALDA, Elias, Reivindicación de Lucrecia Borja. Notas para la historia de los Borja, Valencia.

- Id., Reivindicación de Alejandro VI, Valencia, 1953, $4^{\mathrm{a}}$ ed.

- PASTOR GÓMEZ, Juan (S.I), Borja espiritu universal. (Breve biografia de San Francisco de Borja 1510-1572), Mensajero, Bilbao, 1977, $2^{\mathrm{a}}$ ed. (1970).

- PASTOR ZAPATA, José Luis, Gandia en la baixa Edat Mitjana: La Vila y el Senyoriu dels Borja, CEIC "Alfons El Vell", Gandia, 1992.

- ROBICHON, Jacques, Los Borgia. La trinidad maldita, EDAF, Madrid, 1991 (ed. original en francés: 1989).

- ROO, Pedro de, Los Borjas de la leyenda ante la crífica histórica. Material para una historia del Papa Alejandro VI, sus deudos y su tiempo, Publicaciones de la Academia Borja del Centro de Cultura Valenciana. Valencia, 1952 (la ed. original, Brujas: 1924, constaba de 5 vols. y apareció en inglés).

- SAINT-PAUliEN, San Francisco de Borja, el expiador, Ediciones Paulinas, Madrid, 1963.

- SÁNCHEZ DE LA TORRE, A.; CASTELL, V. y PESET, M., Alejandro VI Papa valenciano, Consel1 Valencià de Cultura (Generalitat Valenciana), València, 1994. 
- SANCHIS SIVERA, José, Algunos documentos y cartas privadas que pertenecieron al segundo Duque de Gandia don Jian de Borja. Notas para la historia de Alerjandro VI, Anales del Instituto General y Técnico de Valencia, Valencia, 1919.

- SCHÜLLER-PIROLI, Susanne, Los Papas Borgia. Calixto III y Alejandro VI, IVEI, Valencia, 1991 (ed. original en alemán: 1979).

- SUAU, Pedro (S:I), Historia de San Francisco de Borja. Tercer General de la Compañia de Jesis 11510-1572), Hechos y Dichos, Zaragoza, 1963 (traducción de la versión francesa de 1910; hay un aprevia, más breve, de 1905).

- VICENT, Manuel, Borja, Borgia, Destino, Barcelona, 1995 (hay también versión en valenciano). 